\title{
Perception and Attitude of Internship Nursing Student Regarding Sexual Harassment
}

\author{
Shadia H. Mehasb ${ }^{1}$, Soad A. Ramadan ${ }^{2}$, Hend A. Elsayed ${ }^{3}$, Dina M. Abd \\ El Salam ${ }^{4}$
}

${ }^{1}$ Professor of Maternal and Newborn Health Nursing, Faculty of Nursing - Ain Shams University, ${ }^{2}$ Asst. Professor of Obstetrics and gynecological Nursing, Faculty of NursingBanha University, ${ }^{3}$ Asst. Professor of Obstetrics and gynecological Nursing, Faculty of Nursing- Banha University, ${ }^{4}$ Clinical Instructor at Nasser institute.

\begin{abstract}
Sexual harassment behavior is one of the most difficult problems facing internship nursing students in recent years that evoke stronger emotional reactions. The purpose of the study was to assess perception and attitude of internship nursing students regarding sexual harassment. A descriptive study was utilized in this study. This study was conducted at the Faculty of Nursing - Banha University. A convenience of 276 female nursing students who were registered in the internship year during time of data collection in the academic year 20162017. Two Instruments were used for collecting data. Instrument one a structured interviewing questionnaire, it consisted of three parts. Part (1) socio-demographic characteristic of internship nursing students, part (2) data about internship training, and Part (3) students' perception regarding sexual harassment. Instrument two included scale of attitude of internship nursing students toward sexual harassment. The result of this study indicated that, $58.7 \%$ of the internship nursing students had an average level of perception regarding sexual harassment. The majority of the internship nursing students had a negative attitude toward sexual harassment. Meanwhile, only $0.4 \%$ had a positive attitude toward sexual harassment. There was a statistically positive correlation between the internship nursing students' total perception and attitude scores regarding sexual harassment. Also, there was a statistically significant relation between the studied sample's level of perception and attitude about sexual harassment and age, residence, and arrangement between brothers and sisters. Conclusion, the study concluded that the internship nursing students have an average level of perception regarding sexual harassment and a negative attitude toward sexual harassment. Therefore, it is recommended that, intensive training program should be implemented to develop intern students' awareness to eliminate sexual harassment.
\end{abstract}

Keywords: sexual harassment, internship nursing students, perception, attitude.

\section{INTRODUCTION}

Sexual harassment is seriously eroding the working excellence which should not be taken likely because it is one of the most difficult problems facing women in recent years. The sexual harassment phenomenon has been a growing public threat in Egypt with neither effective assessment nor solutions for it. It ranges from verbal, physical sexual harassment (Justina et al., 2017).

Sexual harassment describes as any unwelcome sexual advances, requests for sexual favors or other physical and expressive behaviors of a sexual nature. Sexual harassment involves such behavior that is unwanted, intentional, frequently repeated, demeaning, intimidating, cohesiveness, and creates interference with the normal conduct in the work (Lee et al., 2013).

Sexual harassment in the workplace is a problem especially for women; harassment can damage women's prospects for gaining employment, advancement, and wages. In addition, harassment can create an offensive, hostile, and intimidate work 


\section{Perception and Attitude of Internship Nursing Student Regarding Sexual \\ Harassment}

environment that interferes with one's performance and job success. Sexual harassment at the workplace is a violation of human rights. (Hangartner, 2015).

The prevalence rates of sexual harassment behavior among nurses during careers, ranging from 80 to $97 \%$. Nurses are primary caregivers in hospitals and encounter sexual harassment because of the amount of time spent in the hospital to direct patient care. The nature of the nursing profession that it involves working closely with patients and staff members, which often results in an attachment, both physically and emotionally (Hitomi et al., 2016).

Therefore, it is easy for nurses to fall prey to those who take advantage of these situations leading to occurrences of sexual harassment. Many nurses have not been trained to manage sexual harassment situations and didn't report the incidence of sexual harassment. So, sexual harassment threatens the welfare of the nursing students (Grieco, 2015). Most of the time the incidents of sexual harassment are not being reported. It may be due to the lack of awareness regarding sexual harassment, the women may not be aware of the fact that they are actually being sexually harassed and due to the culture of society, also due to humiliation and embarrassment (Gurung et al., 2016).

Sexual harassment in hospital causes many nurses emotional distress, disgust, anger, and it might be associated with nurses' burnout syndrome and high turnover rates. Nursing students suffer from many feelings as frustration, anger, feeling hurt, fear, resentment, helplessness, anxiety, emotional and mental stress to the victims and irritation relating to sexual harassment behavior (Hibino, 2017). Thus, sexual harassment impacts on the nurse's performance and affect the quality of services. This is because its effect is not only to the nurses but also to family members, colleagues, and patients under their care (Ogino et al., 2017).

\section{SIGNIFICANCE OF THE STUDY}

Sexual harassment is not a problem in one country, it is a global issue. The European Commission found that $30 \%$ to $50 \%$ of female employees had experienced some form of sexual harassment (Hejase, 2015). Nursing students' experiences of sexual harassment during clinical training, this cause unsafe education environments and have a negative impact on the nursing student not only mental and physical health but also the satisfaction of clinical practice and positive view for nursing and patient care (Lee et al., 2011).

Nurses are primary caregivers in hospitals and are more likely to face sexual harassment because of the amount of time spent in the hospital to direct patient care. Many nurses are not trained to manage sexual harassment situations (Ali et al., 2015). Therefore, the study was conducted to assess perception and attitude of internship nursing students

\section{PURPOSE OF THE STUDY}

The aim of this study was to assess perception and attitude of internship nursing students regarding sexual harassment.

\section{Research questions}

1) What is the level of internship nursing students' perception regarding sexual harassment?

2) What is the level of internship nursing students' attitude regarding sexual harassment?

3) Is there a relationship between level of internship nursing students' perception and attitude toward sexual harassment? 


\section{Perception and Attitude of Internship Nursing Student Regarding Sexual \\ Harassment}

\section{METHODS}

1- Research design: A descriptive study design was used to achieve the purpose of the study.

2- Setting: The study was conducted at the Faculty of Nursing - Banha Universityare more likely to Sampling:

- Type of sample: Convenience sample.

- Sample size: all female nursing students (276) who were registered in the internship year during the time of data collection were included in the study.

\section{3- Instruments of data collection:}

Two Instruments were used for collecting data:

\section{Instrument I - Structured interviewing questionnaire}

This Instrument was designed by the researcher after reviewing the relative literature. It was designed in the Arabic language. It consisted of 3 parts as follow:

* Part (1) Social characteristics of internship nursing students such as age, marital status, place of residence, number of brothers and sisters, the arrangement between brothers and sister, educational level of parents, marital status of the mother.

* Part (2) Data about internship training they included (hours of the shift, shift time, previous exposure to sexual harassment during the training period, who was the harasser, and the frequency of exposure to sexual harassment.

Part (3) Students' perception regarding sexual harassment. It consisted of 13 items such as; source of information about sexual harassment, definition of sexual harassment, places where sexual harassment increase, types of verbal, physical, and visual harassment. Factors leading to sexual harassment related to female, male, and society. Physical, psychological, and social impact of sexual harassment on the girl. Preventive methods of sexual harassment.

Scoring system for perception regarding sexual harassment

Each item was assigned "one" when response yes and "zero" when response no, the total perception score was calculated by summation of scores of yes responses. Total score of perception ranged from 0-59.Total scoring categorized as following:

- Poor $<50 \%$

- Average $50 \%<75 \%$

- Good $\geq 75 \%$.

Instrument II - Attitude of internship nursing students toward sexual harassment.

This Instrument modified by the researcher after reviewing of literature to assess internship nursing students' attitude toward sexual harassment. It consisted of 10 items, 5 items for positive such as the girl must defend herself against the harasser and his resistance; the girl should talk to her close friend about sexual harassment, etc..... And 5 items for negative such as sexual harassment has a negative effect on the girl psychologically, the personality of the girl influences the reaction towards the sexual harassment position she is exposed to, etc.....

Scoring system for attitude toward sexual harassment

Each item was assigned "two" when response agree, "one" when response uncertain, and "zero" when response disagree. Total attitude score ranged from 0-20. Total scoring categorized as following:

- Negative attitude <50\% 


\section{Perception and Attitude of Internship Nursing Student Regarding Sexual \\ Harassment}

- Uncertain $50 \%<75 \%$

- Positive attitude $\geq 75 \%$.

\section{Content validity and reliability of tools:}

Content validity of tools was assessed by three experts in obstetrics and gynecological nursing fields. Their opinions were elicited regarding the tools format layout, consistency and scoring system. The experts reviewed the tool for clarity of sentences, consistency, appropriateness of content, the sequence of items, accuracy, relevance, comprehensiveness, simplicity, and applicability of tool; minor modifications were done. Finally, the final forms were developed. Reliability of proposed tools was done by Alpha Cronbach test. Cronbach alpha of perception was 0.76 and Cronbach alpha of attitude was 0.81 .

\section{Ethical considerations:}

Ethical aspect was considered before starting the study that includes the following:

- An oral consent was obtained from each female nursing student before starting the data collection.

- Each female was informed about the purpose and benefits of the study at the beginning of interview and time throughout the study.

- Confidentiality was ensured throughout the study process, where personal data were not disclosed, and the females were assured that all data was used only for research purpose.

- There is no harm for the participants.

- Each participant female has the freedom to withdraw from participation at any time.

\section{Administrative design:}

An official permission was obtained from the dean of the faculty of Nursing - Banha University to the head of an administration department who responsible for internship nursing students in the faculty in the academic year 2016-2017 and the Benha University Hospital to take permission to conduct the study after explaining the aim of the study and time of data collection.

\section{Pilot study:}

Pilot study was conducted on $10 \%$ of the total sample (27 students), to evaluate study process, to test the applicability, feasibility, and clarity of the tools as well as to estimate the needed time to fill the questions, and to make sure that items are understood. No modifications were done. The internship nursing students in the pilot study were excluded from the main study sample.

\section{Fieldwork:}

Before collecting data, an official approval was submitted to the dean of the faculty of nursing at Banha University to the head of an administration department who responsible for internship nursing students to collect data after explaining its purpose and arrange the suitable meeting time with students. The researcher took a list of students' number at each department (clinical area) to facilitate reaching to them.

The researcher introduced herself to each student, the aim of the study and component of tools were explained at the beginning of the interview. The researcher assured that the data collected would be treated confidentially and used only for the purpose of the research. The researcher took an oral consent from subjects to participate in the study prior to any data collection.

The field work of the current study was carried out from the beginning of May 2017 and completed at the end of July 2017 covered three months. The researcher determined a fixed four days weekly (Sunday, Monday, Tuesday, and Wednesday) to meet the students. 


\section{Perception and Attitude of Internship Nursing Student Regarding Sexual Harassment}

Two days (Sunday and Monday) from 9 am -2 pm during morning shift and two days(Tuesday, and Wednesday) from $2 \mathrm{pm}-5 \mathrm{pm}$ during afternoon shifts in the previously mentioned setting.

The researcher met the students of each department separately for filling tools of data collection. Ask students to fill the tool I and tool II. Average of nursing students was 5-7 student/day. Time required filling in the sheets ranged from 20-25 minutes.

\section{Statistical design:}

After completion of data collection, the data were organized and tabulated, statistically analyzed using (Statistical Package for the Social Science, version 20, (SPSS). Descriptive statistics, frequency, percent, mean, standard deviation, maximum and minimum were used in the study. Test of significance (Chi-square and Fisher Exact test). Pearson correlation coefficient was used to test the association between the study variables.

- No significant difference obtained at $\mathrm{P}>0.05$.

- Significant difference obtained at $\mathrm{P} \leq$ 0.05 .

- Highly significant difference obtained at $\mathrm{P}>0.001$

\section{Limitation of the study:}

Sensitive and embarrassing proprieties of the study topic.

\section{RESULTS}

Table 1: illustrates that the mean age of the studied sample was $23.15 \pm$ 0.61years. Less than three-quarters $72.1 \%$ of the internship nursing students were single. More than half $56.5 \%$ of them lived in a rural area, and $52.2 \%$ of the internship nursing students had a number of sisters more than the brothers in the family. In addition, nearly one third $31.9 \%$ of them were ranged the third between brothers and sisters.

Table 2: shows that less than twothirds $64.5 \%$ of studied sample worked 12 hours with a mean $9.86 \pm 2.87$ hours. In addition, more than half $55.4 \%$ of internship nursing students worked long day shift.

Table 3: clarifies that there was a positive highly significant correlation between studied sample's total perception and attitude scores regarding sexual harassment $(r=0.624$ and $\mathrm{P}=0.000)$.

Table 4: Illustrates that there was a statistically significant associative relation between the studied sample's level of perception about sexual harassment and age, residence, and arrangement between brothers and sisters $(\mathrm{P} \leq 0.05)$. Meanwhile, there was no statistically significant relation between the studied sample's level of perception about sexual harassment and marital status and number of brothers and sisters $(\mathrm{P} \geq 0.05)$.

Table 5: demonstrates that there was a statistically significant associative relation between the studied sample's level of attitude toward sexual harassment and age, residence, and arrangement between brothers and sisters $(\mathrm{P} \leq 0.05)$. Meanwhile, there was no statistically significant relation between the studied sample's level of attitude about sexual harassment and marital status and number of brothers and sisters $(\mathrm{P} \geq 0.05)$.

Figure 1: shows that more than half $(58.7 \%)$ of nursing students had average level of knowledge regarding sexual harassment.

Figure 2: Distribution of the studied sample according to the total level of attitude toward sexual harassment $(n=276)$. This figure shows that more than half $(54.7 \%)$ of nursing students had negative attitude regarding sexual harassment. 
Table (1): Distribution of the studied sample according to their demographic characteristics $(n=276)$.

\begin{tabular}{|c|c|c|}
\hline Demographic characteristics & No. & $\%$ \\
\hline \multicolumn{3}{|l|}{ Age (years) } \\
\hline 22 & 25 & 9.1 \\
\hline 23 & 193 & 69.9 \\
\hline 24 & 50 & 18.1 \\
\hline 25 & 8 & 2.9 \\
\hline Mean \pm SD & \multicolumn{2}{|c|}{$23.15 \pm 0.61$} \\
\hline \multicolumn{3}{|l|}{ Marital status } \\
\hline Single & 199 & 72.1 \\
\hline Married & 77 & 27.9 \\
\hline \multicolumn{3}{|l|}{ Residence } \\
\hline Urban & 120 & 43.5 \\
\hline Rural & 156 & 56.5 \\
\hline \multicolumn{3}{|l|}{ Number of brothers and sisters } \\
\hline Brothers & 132 & 47.8 \\
\hline Sisters & 144 & 52.2 \\
\hline \multicolumn{3}{|l|}{ Arrangement between brothers and sisters } \\
\hline First & 74 & 26.8 \\
\hline Second & 71 & 25.7 \\
\hline Third & 88 & 31.9 \\
\hline Fourth & 43 & 15.6 \\
\hline
\end{tabular}

Table (2): Distribution of the studied sample according to nature of work in intern training $(n=276)$.

\begin{tabular}{||l|c|c|}
\hline \multicolumn{1}{|c|}{ Variable } & No. & \% \\
\hline Working hours & 98 & 35.5 \\
\hline 6 hours & 178 & 64.5 \\
\hline 12 hours & \multicolumn{2}{|c|}{$9.86 \pm 2.87$} \\
\hline Mean \pm SD & 83 & 30.1 \\
\hline Shift time & 15 & 5.4 \\
\hline Morning shift (8 Am- 2 Pm) & 153 & 55.4 \\
Afternoon shift (2 Pm- 8 Pm) & 25 & 9.1 \\
Long day shift (8 Am- 8 Pm) & \multicolumn{2}{|c|}{} \\
Night shift (8 Pm- 8 Am)
\end{tabular}


Table (3): Correlation between studied sample ' total knowledge and attitude scores regarding sexual harassment $(n=276)$.

\begin{tabular}{|c|c|c|}
\hline \multirow{2}{*}{ Variable } & \multicolumn{2}{|c|}{ Total knowledge score } \\
\cline { 2 - 3 } & $\mathbf{R}$ & P value \\
\hline Total attitude score & 0.624 & $0.000^{* *}$ \\
\hline
\end{tabular}

Table (4): Associative relation between of the studied sample' lev el of knowledge about sexual harassment and demographic characteristics $(\mathbf{n}=\mathbf{2 7 6})$.

\begin{tabular}{|c|c|c|c|c|c|c|c|c|}
\hline \multirow{2}{*}{$\begin{array}{l}\text { Level of knowledge } \\
\text { Demographic } \\
\text { characteristics }\end{array}$} & \multicolumn{2}{|c|}{$\begin{array}{l}\text { Good } \\
\text { n= } 5\end{array}$} & \multicolumn{2}{|c|}{$\begin{array}{c}\text { Average } \\
\mathrm{n}=162\end{array}$} & \multicolumn{2}{|c|}{$\begin{array}{c}\text { Poor } \\
\text { n= } 109\end{array}$} & \multirow[t]{2}{*}{$\mathrm{X}^{2} / \mathrm{FET}$} & \multirow[t]{2}{*}{ P-value } \\
\hline & No & $\%$ & No & $\%$ & No & $\%$ & & \\
\hline \multicolumn{9}{|l|}{ Age ( years) } \\
\hline $22-$ & 1 & 20.0 & 7 & 4.3 & 17 & 15.6 & & \\
\hline 23- & 4 & 80.0 & 123 & 76.0 & 66 & 60.6 & 15.232 & $0.019^{*}$ \\
\hline 24- & 0 & 0.0 & 26 & 16.0 & 24 & 22.0 & & \\
\hline 25- & 0 & 0.0 & 6 & 3.7 & 2 & 1.8 & & \\
\hline \multicolumn{9}{|l|}{ Marital status } \\
\hline Single & 3 & 60.0 & 116 & 71.6 & 80 & 73.4 & 0.474 & 0.789 \\
\hline Married & 2 & 40.0 & 46 & 28.4 & 29 & 26.6 & & \\
\hline \multicolumn{9}{|l|}{ Residence } \\
\hline Urban & 4 & 80.0 & 77 & 47.5 & 39 & 35.8 & 6.425 & $0.040^{*}$ \\
\hline Rural & 1 & 20.0 & 85 & 52.5 & 70 & 64.2 & & \\
\hline \multicolumn{9}{|c|}{ Number of brothers and sisters } \\
\hline Brothers & 1 & 20.0 & 84 & 51.9 & 47 & 43.1 & 3.571 & 0.168 \\
\hline Sisters & 4 & 80.0 & 78 & 48.1 & 62 & 56.9 & & \\
\hline \multicolumn{9}{|c|}{ Arrangement between brothers and sisters } \\
\hline First & 1 & 20.0 & 49 & 30.2 & 24 & 22.0 & 12.540 & $0.051^{*}$ \\
\hline Second & 2 & 40.0 & 48 & 29.6 & 21 & 19.3 & & \\
\hline Third & 2 & 40.0 & 47 & 29.0 & 39 & 35.8 & & \\
\hline Fourth & 0 & 0.0 & 18 & 11.2 & 25 & 22.9 & & \\
\hline
\end{tabular}

Table (5): Associative relation between of the studied sample' level of attitude toward sexual harassment and social characteristics $(n=276)$. 


\begin{tabular}{|c|c|c|c|c|c|c|c|c|}
\hline \multirow{2}{*}{$\begin{array}{l}\text { Lemel of attitude } \\
\text { characteristics }\end{array}$} & \multicolumn{2}{|c|}{$\begin{array}{c}\text { Positive } \\
\mathbf{n}=1\end{array}$} & \multicolumn{2}{|c|}{$\begin{array}{c}\text { Uncertain } \\
\mathbf{n = 1 2 4}\end{array}$} & \multicolumn{2}{|c|}{$\begin{array}{c}\text { Negative } \\
\mathrm{n}=151\end{array}$} & \multirow[t]{2}{*}{$\mathbf{X}^{2} / \mathbf{F E T}$} & \multirow[t]{2}{*}{ P-value } \\
\hline & No & $\%$ & No & $\%$ & No & $\%$ & & \\
\hline \multicolumn{9}{|l|}{ Age ( years) } \\
\hline 22- & 0 & 0.0 & 9 & 7.3 & 16 & 10.6 & \multirow[t]{4}{*}{13.751} & \multirow[t]{4}{*}{$0.033^{*}$} \\
\hline 23- & 1 & 100.0 & 100 & 80.6 & 92 & 60.9 & & \\
\hline 24- & 0 & 0.0 & 13 & 10.5 & 37 & 24.5 & & \\
\hline 25- & 0 & 0.0 & 2 & 1.6 & 6 & 4.0 & & \\
\hline \multicolumn{9}{|l|}{ Marital status } \\
\hline Single & 1 & 100.0 & 89 & 71.8 & 109 & 72.2 & \multirow[t]{2}{*}{0.394} & \multirow[t]{2}{*}{0.821} \\
\hline Married & 0 & 0.0 & 35 & 28.2 & 42 & 27.8 & & \\
\hline \multicolumn{9}{|l|}{ Residence } \\
\hline Urban & 1 & 100.0 & 68 & 54.8 & 51 & 33.8 & \multirow[t]{2}{*}{13.598} & \multirow[t]{2}{*}{$0.001 *$} \\
\hline Rural & 0 & 0.0 & 56 & 45.2 & 100 & 66.2 & & \\
\hline \multicolumn{9}{|c|}{ Number of brothers and sisters } \\
\hline Brothers & 0 & 0.0 & 51 & 41.1 & 81 & 53.6 & \multirow[t]{2}{*}{5.193} & \multirow[t]{2}{*}{0.075} \\
\hline Sisters & 1 & 100.0 & 73 & 58.9 & 70 & 46.4 & & \\
\hline \multicolumn{9}{|c|}{ Arrangement between brothers and sisters } \\
\hline First & 0 & 0.0 & 39 & 31.5 & 35 & 23.2 & \multirow[t]{4}{*}{14.385} & \multirow[t]{4}{*}{$0.026^{*}$} \\
\hline Second & 1 & 100.0 & 34 & 27.4 & 36 & 23.8 & & \\
\hline Third & 0 & 0.0 & 27 & 21.7 & 61 & 40.4 & & \\
\hline Fourth & 0 & 0.0 & 24 & 19.4 & 19 & 12.6 & & \\
\hline
\end{tabular}

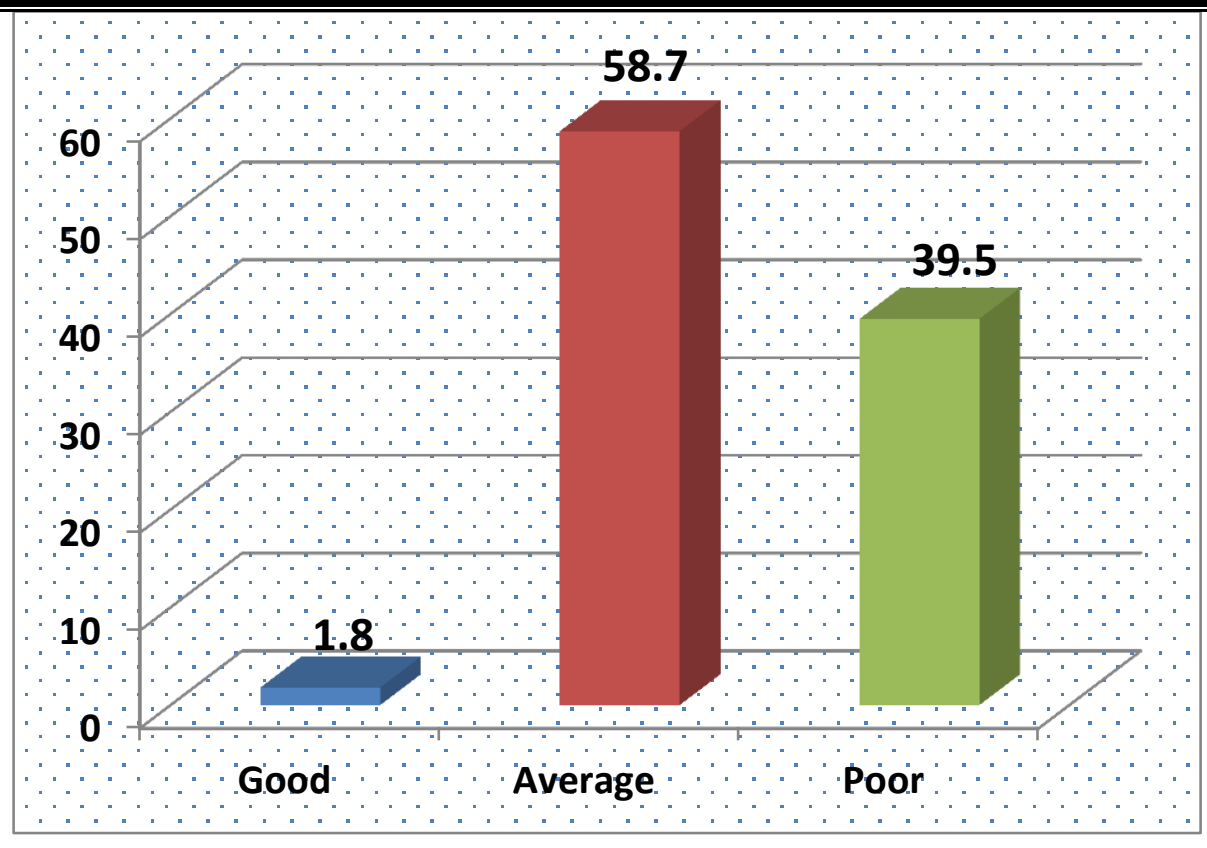

Figure (1): Distribution of the studied sample according to total level of knowledge regarding sexual harassment $(\mathbf{n}=\mathbf{2 7 6})$. 


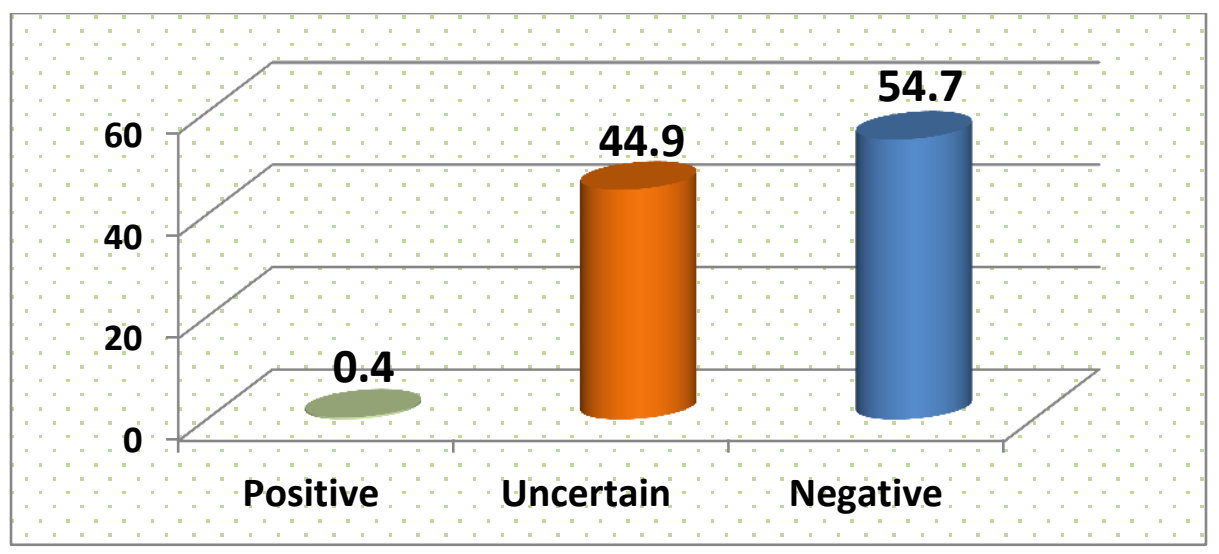

Figure (2): Distribution of the studied sample according to total level of attitude toward sexual harassment $(n=276)$

\section{DISCUSSION}

Nurses are primary caregivers in hospitals and are more likely to face sexual harassment because of the amount of time spent in the hospital to direct patient care. Sexual harassment against nurses has an effect on health, job performance and overall patient care. Many nursing students are not trained to manage sexual harassment situations. Knowledge on sexual harassment equips the students to face such situation courageously Gurung et al., (2016).

The aim of the present study was to assess perception and attitude of internship nursing students regarding sexual harassment. This aim was significantly achieved through a descriptive study design that answered the research questions; what is the level of internship nursing students' perception regarding sexual harassment?, what is the level of internship nursing students' attitude regarding sexual harassment? and is there a relationship between level of internship nursing students' perception and attitude toward sexual harassment?

The study findings will be discussed under four main sections: characteristics of the studied sample and internship training, internship nursing students' perception regarding sexual harassment, internship nursing students' attitude toward sexual harassment, and the correlation between the studied sample ' total knowledge and attitude scores regard sexual harassment.
The results of the present study revealed that the mean age of the studied sample was $23.15 \pm 0.61$ years. Less than three-quarters of the internship nursing students were single. The current result is nearly similar to Muzamil, (2017) who found that the higher percentage of the studied sample age $64.7 \%$ was ranged from 20-23 years old, and the majorities of them $82.1 \%$ were not married. Also, Shebl et al., (2017) who concluded that $64.7 \%$ of female students were within age $22-23$ and $82.1 \%$ was single. The younger age may be a reflection of lack of work experience, resulting in the internship nursing students' inability to handle potentially difficult situations.

Concerning residence, the present result reported that more than one-half of the internship nursing students lived in the rural area; the result of the present study is agreement with Suhaila and Rampal, (2012) who reported that more than three quarters $78.3 \%$ of the sample was from the rural area. Also, Nazari et al., (2017) reported that about two-thirds $66.3 \%$ of the studied sample lived in rural area. However, the present result disagrees with the findings of a study conducted Kisa and Dziegielewski, (2013) who found that more than half $56 \%$ of the studied sample was from urban areas. Related to number of brothers and sisters in the family, the result of the present study revealed that about one half of the studied sample had sister more than the brother in 
family, the present result agreed with Robbins et al., (2015) who reported that more than two-thirds $68.8 \%$ of study sample had sisters more than brothers. Also, the current result supported by Kamel, (2012) who found that more than one-half $55.7 \%$ of nursing students had sisters more than brothers. This may be due to brothers within family consider a close person to the girl who can advise and talk with here about such topics.

The current study result revealed that nearly one-third of studies sample were ranged the third between brothers and sisters. The present result is in contrast with Oyedunni, (2013) who found that more than half $51.6 \%$ of the studied sample was the first in their families. Also, Mohammed and Hashish, (2014) found that less than half $46.9 \%$ were the first daughter in the family.

Regarding nature of work in intern training, the current study findings showed that less than two-thirds of studied sample worked 12 hours and more than half of them worked long day shift. This finding was supported by Onat and Dinc, (2012) who found that $82.1 \%$ of the sample exposed to harassment during the day shift. In the same line, Lee et al., (2011) reported that more than two fifths $43.6 \%$ of the female who exposed to sexual harassment worked 12 hours during the day. The current result contrasted with Suhaila and Rampal, (2012) who found that most of the sexual harassment episodes occurred during the evening or night shifts. As a result of the lack of control and policies which prevent sexual harassment in the workplace.

The findings of the current study reported that more than half of the internship nursing students had an average level of perception regarding sexual harassment and the minority had a good level of perception. The present result supported by Cogin and Fish, (2017) who reported that majority of the nursing students $82.4 \%$ had an average perception and $30.2 \%$ had a good perception regarding sexual harassment. Also, Bursik and Gefter, (2011) showed that $50.8 \%$ of the studied sample had an average knowledge about sexual harassment and nearly one third
$31.9 \%$ had poor knowledge. This is contrasted with Dane et al., (2010) who found that $36.4 \%$ had an average perception. This may be due to the sensitivity of the topic and embarrassment of females to talk about it.

The study noticed that, more than half of the internship nursing students had a negative attitude regarding sexual harassment. The current result supported by Hibino, (2016) who found that $75.5 \%$ of female students had a negative reaction toward sexual harassment. Because of lack of knowledge about sexual harassment and they had not received any type of training on how to deal with harassment behavior.

\section{Correlation between total knowledge and attitude scores regarding sexual harassment:}

The result of the current study clarified that there was a statistically positive correlation between studied sample's total perception and attitude scores regarding sexual harassment. The present result is congruent with Fiedler and Hamby, (2014) who stated that the female with adequate knowledge and information about sexual harassment had positive attitude and reaction toward the situation. On the other hand, Terpstra and Cook, (2013) showed that there was a positive relationship between knowledge about sexual harassment and attitude toward it. This may be due to perception about the facts around sexual harassment and solutions to eliminate sexual harassment have an effect on the attitude and response to the situations of sexual harassment.

The current study showed that there was a statistically significant relation between the studied sample's level of perception about sexual harassment and age, residence, and arrangement between brothers and sisters. The present result supported by Gurung et al., (2016) who found that there is a significant association between knowledge on sexual harassment and age of sample $(\mathrm{P}=0.03)$. In contrast Chaudhuri, (2017) who reported that there is no statistically significant relationship between knowledge on sexual harassment and age $(\mathrm{P}=0.083)$. 
Also, Nazari et al., (2017) found that there is a statistically significant relationship between knowledge on sexual harassment and residence of the studied sample. Meanwhile, the current result contrasted with Samir et al., (2012) who showed that There was no significant association between the residence and the perception about sexual harassment $(\mathrm{P}=0.27)$.

Finally, the current result of the present study found that there was a statistically significant relation between the studied sample's level of attitude toward sexual harassment and age, residence, and arrangement between brothers and sisters. The present result supported by Yee et al., (2015) who found that there was a relationship between attitude toward sexual harassment. Also, Valente and Bullough, (2015) showed a statistically significant association between residence and attitude toward sexual harassment $(p<.01)$. In contrast, with the current result Kisa et al., (2016) who reported that there is no association between attitude toward sexual harassment and residence $(\mathrm{p}=0.58)$. Additionally, Oyedunni, (2013) found that there was a statistically significant relationship between the level of attitude and arrangement between brother and sisters in the family.

\section{CONCLUSION}

The findings of the current study concluded that the main source of information about sexual harassment was media. The majority of the internship nursing students had an average level of perception regarding sexual harassment. Meanwhile, the minority had a good level of perception regarding sexual harassment. Also, the majority of the internship nursing students had a negative attitude regarding sexual harassment. On the other hand, there was a statistically positive correlation between the internship nursing students' total perception and attitude scores regarding sexual harassment. There was a statistically significant relation between the internship nursing students' level of perception and attitude about sexual harassment and age, residence, and arrangement between brothers and sisters. There for, the study's questions were answered.

\section{RECOMMENDATIONS}

In the light of the results of the present study, the following recommendations are suggested:

- An intensive awareness program should be implemented to develop intern students' awareness to eliminate sexual harassment.

- Increase knowledge of nursing students about sexual harassment should be a part of the academic and professional preparation of intern students at the faculty of nursing.

- Further researches are needed to be conducted to replicate the present study to increase awareness for breaking the female silence to take appropriate action towards harassment.

\section{REFERENCES}

Ali,E., Elsabagh,H., Saied,SH., and Zayed,H.,: Sexual harassment against nursing staff in Tanta University Hospitals, Egypt, Journal of the Egyptian Public Health, 2015; p.95.

Bursik, K., \& Gefter, J.: Still Stable After all These Years: Perceptions of Sexual Harassment in Academic Contexts. The Journal of Social Psychology, 2011; 101(7), 335- 352.

Chaudhuri,P.,: Experiences of sexual harassment of women health workers in four hospitals in Kolkata, India, Reprod Health Matters 2017; 15, 221 239.

Cogin,J., and Fish,A.,: Sexual harassmenta touchy subject for nurses. Jornal of Health Organization Management, 2017; 23, 442-462.

Dane,A., Pinsof,D., and Riggs,L.,: Sexual Harassment as an occupational hazard 
in nursing, Basic and applied social psychology, 2010; 17(4), 564-576.

Fiedler,A., and Hamby,E.,: Sexual harassment in the workplace: nurses' perceptions, Journal of Nursing Administration, 2014; 30, 497-513.

Grieco,A.,: scope and nature of sexual harassment in nursing, the journal of sex research, 2015; 23(2),P. 263.

Gurung,A., Priyadarshini, S., and Margaret, B.,: Knowledge of Sexual Harassment among the Undergraduate students in Udupi district, Nitte University Journal of Health Science, 2016; 6(2), 4- 20.

Hangartner,R.,: The Association Between Sexual Harassment and Sociality Among College Women, Journal of sex Research, 2015; 23(2) 10-19.

Hejase,H.,: Sexual Harassment in the Workplace: An Exploratory Study from Lebanon, journal of Management Research, 2015; 7(1),p. 110.

Hibino,S.,: Sexual harassment of female nurses by patients in Japan, Journal of Nurses Scholarship, 2016; 38(4), 400415.

Hibino,Y.,: sexual harassment in healthcare: nursing and gender, Nova science publishers, Inc., 2017; 12 , P. 67.

Hitomi, Y., Kambayashi, Y., Nakamura, H., and Hibino, Y.,: Exploring Factors Associated With the Incidence of Sexual Harassment of Hospital Nurses by Patients, journal of nursing scholarship, 2016; 41(2), P.124.
Justina,M., Philipa,I., and Oyaziwo,A.,: A Survey of Teachers' and Students' Perception of Sexual Harassment in Tertiary Institutions of Edo State, Nigeria, International Multidisciplinary Journal, Ethiopia, 2017; 5 (5), P. 413.

Kamel,K.,:Faculty of Nursing student's perception regarding Sexual Assault and their expected reaction to it, master degree, 2012; p. 5.

Kim,J.,: A Longitudinal Study On The Relationship Between Workplace Harassment And Cyberloafing, California State University, Long Beach, 2012; 1-340.

Kim,T., Kwon,Y., and Kim,M.,: Experience and Perception of Sexual Harassment During the Clinical Practice and Selfesteem among Nursing Students, Korean journal of Women Health Nursing, 2017; 23 (1), 23- 41.

Kisa,A., and Dziegielewski,S.,: Sexual harassment of female nurses in a hospital in Turkey, Health Survey Manage Research, 2013; 9, 243-253.

Kisa,A., Dziegielewski,S., and Ates, M.,: Sexual harassment and its consequences:a study within Turkish hospitals, Journal of Health and Social Policy, 2016; 15(2), 77-94.

Lee, S., Song, J., and Kim, S.,: Experience and perception of sexual harassment during the clinical practice of Korean nursing students, Asian Nursing Research, 2011; 5,pp.170-176.

Lee,Y., Kim,K., and Choi,S.,: Awareness levels and influencing factors of 
sexual harassment and gender egalitarianism among college students. Journal of Korean Academic Community Health Nurse, 2013; 24(1), P. 42.

Mohammed,F., and Hashish, K.,: Sexual violence against females and its impact on their sexual function Egyptian Journal of Forensic Sciences, 2014; 5 (3), 96-102.

Muzamil,S.,: Sexual Harassment at Clinical Placement: Impact Towards Female Nursing Students, Journal of Nurses Scholarship, 2017; 76(5), 2-22.

Nazari, M.I., Kum, L.C. and Foong, C.B.: Factors Influencing Sexual Harassment In The Malaysian Workplace, Asian Academy of Management Journal, 2017; Vol. 12, No. 2, 15-31.

Onat,G., and Dinc,H.,: Sexual harassment among health workers and students. International Journal of Human Science, 2012; 9, 21-34.

Oyedunni,S.,: Experience of sexual harassment and coping strategies among students of the school of nursing of a tertiary hospital in Southwest Nigeria International Journal of Nursing and Midwifery, 2013; 5(4), 70-89.

Robbins,I., Bender,P., and Finnis,J.,: Sexual harassment in nursing. England Journal of Advance Nursing, 2015; 25(1), 163-176.
Shebl,A., Elmashad, H., and Hassan,S.,: Sexual Harassment Phenomena among Female Students at Mansoura University, IOSR Journal of Nursing and Health Science, 2017; 6(1), 37-45.

Suhaila,O., and Rampal,K.,: Prevalence of sexual harassment and its associated factors among registered nurses working in government hospitals in Malaysia, Journal of Occupational Health, 2012; 67, 506-517.

Suhaila, O., and Rampal, K.,: Prevalence of sexual harassment and its associated factors among registered nurses working in government hospitals in Malaysia, Journal of Occupational Health, 2012; 67, 506-517.

Terpstra, E., and Cook, E.,: Complaint characteristics and reported behavior and consequences associated with formal sexual harassment charges, Journal of Applied Personnel Psychology, 2013; 38(2), 559-547.

Valente, S., and Bullough, V., Sexual harassment of nurses in the workplace, Journal of Nursing Care Quality, 2015; 19(3), 234- 249.

Yee, M., Alagappar, p., and Ngeow, Y.,: Differences in the Perception of Sexual Harassment by Gender and Ethnicity among Selected Malaysian Undergraduates, Gender, Technology and Development, 2015; 19(2), 206-2 